NBER WORKING PAPER SERIES

\title{
INTERNATIONAL PATENTING AND \\ TECHNOLOGY DIFFUSION
}

Jonathan Eaton

Samuel Kortum

Working Paper No. 4931

\author{
NATIONAL BUREAU OF ECONOMIC RESEARCH \\ 1050 Massachusetts Avenue \\ Cambridge, MA 02138 \\ November 1994
}

We have benefited from discussions with David Andolfatto, John Helliwell, Stephen Parente, Jonathan Putnam, and Ed Roman. Earlier versions were presented at the NBER, the Winter Meetings of the Econometric Society, Northeastem University, the North East Universities Development Conference, CEPREMAP, the University of Western Ontario, and Princeton University. Akiko Tamura provided excellent research assistance. We take responsibility for any errors. We gratefully acknowledge the support of the National Science Foundation under Grant No. SBR 9309935-001. This paper is part of NBER's research programs in Growth, International Trade and Investment, and Productivity. Any opinions expressed are those of the authors and not those of the Federal Reserve System or the National Bureau of Economic Research.

(c) 1994 by Jonathan Eaton and Samuel Kortum. All rights reserved. Short sections of text, not to exceed two paragraphs, may be quoted without explicit permission provided that full credit, including $(0$ notice, is given to the source. 


\title{
INTERNATIONAL PATENTING AND TECHNOLOGY DIFFUSION
}

\begin{abstract}
We model the invention of new technologies and their diffusion across countries. Our model predicts that, eventually, all countries will grow at the same rate, with each country's productivity ranking determined by how rapidly it adopts inventions. The common growth rate depends on research efforts in all countries, while research effort is determined by how much inventions earn at home and abroad. Patents affect the return to invention. We relate the decision to patent an invention internationally to the cost of patenting in a country and to the expected value of patent protection in that country. We can thus infer the direction and magnitude of the international diffusion of technology from data on international patenting, productivity, and research. We fit the model to data from the five leading research economies. The parameters indicate how much tech is logy flows between these countries and how much each country earns from its inventions domestically and elsewhere. Our results imply that foreign countries are important sources of technology even though countries earn most of their return to innovation at home. For example, about half of U.S. productivity growth derives from foreign technology yet U.S. investors earn 98 per cent of the revenue from their inventions domestically.

Jonathan Eaton

Department of Economics

Boston University

270 Bay State Road

Boston, MA 02215

and NBER

\author{
Samuel Kortum \\ Board of Governors of the \\ Federal Reserve System \\ Mail Stop 82 \\ Washington, DC 20551 \\ and NBER
}




\section{Introduction}

A basic question is the role of technology in explaining productivity differences across countries. One hypothesis is that technology is highly mobile across borders while capital is not. The implication is that capital investment rather than technology explains differences in per capita income. ${ }^{1}$ Another hypothesis is that capital is highly mobile internationally while countries are slow to adopt foreign technology. In this case income differences derive from differences in the rate at which different countries innovate and adopt inventions from elsewhere. ${ }^{2}$ To assess the plausibility and quantitative implications of this second hypothesis we develop and implement empirically a model of how and where inventions occur, how they diffuse domestically and internationally, and how they give rise to increases in productivity.

While economists have devoted substantial attention to measuring the degree of capital mobility internationally, less is known about the international mobility of technology. The problem is observing the creation of knowledge and its diffusion over time and across space. ${ }^{3}$ In this paper we exploit data on international patenting and research effort to infer the sources

\footnotetext{
${ }^{2}$ Barro and Xala-I-Martin (1992) and Mankiw, Romer, and Weil (1992) pursue the empirical implications of this hypothesis. Several puzzles are that: (i) the implied values of capital's share and of interest rate differentials are implausibly large; (ii) levels of income per capita converge at rates that are too slow given rensonahle parameter values; (iii) the growth rates of total factor productivity, which take capital accurnulation into account, continue to exhibit convergence (Dowrick and Nguyen (1989) and Helliwell and Chung (1891)); (iv) technology appears to diffuse more rapidly domestically than acroes borders (Lichtenberg(1992)).

${ }^{2}$ Gerschenkron (1962) interprets the comparative experiences of different Europenn countries and Japan during their industrial revolutions in terms of the diffusion of tochnology. Nelson and Pbelps (1966), Krugman (1979), Gomulka (1990), Grossman and Helpman (1991), Segerstrom (1991), Young (1993), and Parente and Prescott (1994), among others, provide alternative formalizations of international diffusion. Grosoman and Helpman (1994), Fagerbers (1994), and Dinopoulos (1094) survey the literature.

${ }^{2}$ Neverthelees, Pavitt and Soete (1082), Fagerbers (1087), Benhabib and Spiegel (1992), Coe aod Helpman (1993), and Evenson and Englander (1994) eatimate international technology diffusion using alternative approsches. We depart from these other etudien in embedding tochnological diffusion, endogenous research activity, and the patenting decision into an intertemporal general oquilibrium framework.
} 
and the spread of technological progress. Data on employment of R\&D scientists and engineers provide a measure of the inputs used to invent while data on international prinnting indicate where inventions occur and where their inventors think they might be adopted. However, patenting measures technology diffusion only imperfectly and indirectly: Many inventions are not patented at all, or at least not patented everywhere they are used, while many ideas that are patented never constitute significant innovations. Moreover, the costs of patenting and the benefit of protection vary across countries, both because of differences in patent laws and the strength of protection, and because of differences in market size.

To address these problems we incorporate the inventor's decision to patent in different countries into a model of research and technology diffusion. The model identifies features of an invention and characteristics of national economies and patent systems that determine the return to patenting. We can thus isolate the role of technology diffusion in the patenting decision.

In our model, production in each country, as in Grossman and Helpman (1991), uses a fixed continuum of inputs to make a homogeneous output. Researchers in each country search for inputs of higher quality that potentially can be used anywhere in the world. We follow Kortum (1994) in assuming that researchers draw from a given distribution of ideas of different quality. Variation in the quality of ideas explains why inventors seek patent protection for some ideas in many countries while others are protected in only one country or not at all. ${ }^{3}$

Ideas are adopted in different countries with a lag that can vary according both to where the ides originates and to where it is used. 6 Since the processes of invention and of production are intimately linked, the diffusion of ideas domestically may be much more rapid than their

\footnotetext{
4Penroes (1951) provides the clumic diecumion of the international patenting system.

${ }^{8}$ Putnam (1993) finds that, of inventions that are patented in at least one country, 72 per cent are patentad only there while 18 per cent are patented in three or more countries.

'Abramovitz (1992) describea the eace with which countries can adopt each other's technologies in terms of their degree of "technological consruence".
} 
diffusion across borders, but our model does not impose this ordering a priori

An idea constitutes an innovation in a country if it surpasses the state of the art there. As the distribution of technology in a country advances, a smaller fraction of ideas are innovations. An implication is that a less inventive country will eventually grow at the same rate as more inventive ones since it is able to draw more innovations from the "technology gap" between itself and others. The technology gaps between countries that sustain a common growth rate determine long-run relative productivity levels.

We incorporate the patenting decision into our model of invention and diffusion as follows: We assume that if an idea constitutes an innovation in a country then the inventor appropriates the rent it earns there as long as (1) no better invention has rendered it obsolete and (2) it has not been successfully imitated. Patent protection reduces the hazard of imitation. It need not provide perfect protection from imitation, nor is imitation necessarily immediate if the inventor fails to patent.

The rate at which an ides diffuses to a country is unaffected by the inventor's decision to patent there. At the same time, more rapid difusion into a country increases the incentive to patent there since the rewards will be achieved sooner. Patent protection nevertheless does have real effects in that it influences the return to R\&D.

At the time of invention, the inventor knows the sbsolute quality of the idea but not how much, if any, it advances the state of the art in different countries. Hence the inventor must decide whether or not to apply for a patent in a country without knowing how much the ides will ever earn there. Inventors will patent some ideas widely and others in few places, or nowhere at all. Some unpatented ideas may someday significantly advance the state of the art, while some widely-patented ideas will turn out to be duds. An inventor will seek wider protection for a high-quality ides, since it is more likely to be an innovation.

Our model identifies market size, the cost of patenting, the strength of intellectual property protection, the average level of productivity, and, most critical for our analysis, the speed at 
which the country can absorb ideas into its technology as characteristics of a country relevant to the patent decision. ${ }^{?}$

We fit the steady state of our model to data on growth, relative productivities, research scientists and engineers, and international patenting from the five major research economies: France, Germany, Japan, the United Kingdom, and the United States. We decompose growth in output per worker in each of the five countries into what is contributed by innovations from each of the five. We also decompose earnings from innovations in each country into what emanates from each of the five. We find that foreign countries are important sources of technology even though countries earn most of their return to innovation domestically. For example, nearly half of U.S. productivity growth derives from foreign technology. Nevert heless, U.S. inventors earn 98 per cent of the revenues from their inventions at home. We conclude with several simulation experiments. Eliminating diffusion between the United States and the rest of the world, for example, would lower world growth by almost half a percentage point and leave the United States far behind the other four. At the other extreme, if diffusion were as rapid between countries as within them then world growth would be 2.3 percentage points higher than the base case level. We find that patent protection has only a modest impact on growth.

We proceed as follows: In section 2 below we present the model and then, in section 3 , characterize its steady state. In section 4 we parameterize the steady state with data from the five leading research economies. In section 5 we decompose the sources of growth and the returns to innovation among these countries, and offer the results of the simulation of several alternative scenarios that allow for different rates of international technology diffusion and

\footnotetext{
${ }^{7}$ An we discuseed, an idea in more likely to advance the state of the art in a country where the level of productivity is low. This does not mean that an inventor is nocessarily more likely to apply for protection in a poor country, however. A country is likely to be poor preciecly because it adopts innovatione slowly, roducing the return to patenting there.
} 
different levels of intellectual property protection. Section 6 offers some concluding remarks.

\section{The Model}

Since our model is intricate, we review its components before describing each in detail Production of output, described in section 2.1, combines a continuum of inputs of varying quality, which are themselves produced by labor. An alternative activity for workers is doing research to come up with ideas for better inputs. Section 2.2 describes how ideas are produced and how they disseminate. A key variable describing a country at any moment is the stock of ideas that have reached it up to that point. Our assumptions about production and diffusion imply a relationship between this stock of knowledge and the distribution of technologies in the country. Section 2.3 derives this distribution and its dynamics. In 2.4 we show how labor productivity relates to the stock of ideas through the implied distribution of lechnologies.

We make assumptions about market structure, with implications for pricing and firm profit, which we discuss in 2.5. These assumptions also have implications, which we turn to in 2.6, about the value of having an innovation adopted in a country, depending on whether or not it is patented. We can thus infer the return to patenting in a country, and relate the decision to patent an idea to the quality of the idea, the speed of diffusion, the cost of patenting, and market size. This we do in 2.7. Putting these things together we then calculate, in 2.8 , the the expected value of an idea, incorporating the optimal patenting decision in each country.

The value of ideas determines the return to doing $R \& D$ while labor productivity determines the opportunity cost of this activity. In 2.9 and 2.10 we relate the two to solve for the equilibrium amount of R\&D effort and the wage. 


\subsection{Production}

We consider a world consisting of $n=1, \ldots, N$ countries. Output in country $n\left(Y_{n}\right)$ is produced by combining intermediate inputs subject to a constant-returns-to-scale Cobb-Douglas production function,

$$
\ln \left(Y_{n t} / J\right)=J^{-1} \int_{0}^{J} \ln \left[Z_{n t}(j) X_{n t}(j)\right] d j
$$

where $X_{n t}(j)$ is the quantity of input $j$ produced at time $t$ in country $n$ and $Z_{n t}(j)$ is the quality of that input. (See the Appendix for a list of symbols.) The range of inputs is fixed over time and the same across countries. Output is homogeneous and tradable across countries, while inputs are nontraded. ${ }^{8}$ We choose units so that to produce any input at rate $x$ requires local labor services at rate $x$. Productivity differences across countries result from differences in the quality of inputs.

Within a country, the quality of inputs improves over time. These improvements derive from research performed both domestically and abroad.

\subsection{Ideas}

An idea is our basic unit of research output. While we assume that all workers in each country are equally productive producing goods, we allow workers to differ in their productivities as researchers. In particular, we assume that in country $n$ with a total labor force of $L_{n t}$, if workers are ranked according to their productivity as researchers, a worker of rank $j$ produces ideas at a stochastic rate $\alpha_{n t} \beta\left(\frac{j}{L_{n t}}\right)^{\beta-1}$. The parameter $\alpha_{n t}$ reflects the overall productivity of researchers in country $n$ at time $t$ while $\beta$ reflects the rate at which research productivity declines as less talented workers become researchers. We assume that workers are compensated

\footnotetext{
"By asouming a single, bomozenoous tradable output we prevent inventions from having any effect on the terms of trade between countrie. While it would be interesting to consider the implications of invention for the terms of trade, we preclude the possibility bere in order to focus purely on the implications of innovation for productivity.
} 
in proportion to their productivity in either production or research. Hence the workers who are the most productive at doing research will become researchers. Thus if $R_{\text {nt }}$ workers in country $n$ at time $t$ are doing research, they will create ideas at a rate $\alpha_{n t} L_{n t}^{1-\beta} R_{n t}^{\beta}$.

There are several dimensions to an idea: its quality, its sector of use, and the time until it diffuses to each country. An idea's quality is a random variable $Q$ drawn from the cumulative distribution function, $F(q)=\operatorname{Pr}[Q<q]$. The quality of an ides is common to all countries to which it diffuses. We assume a Pareto distribution of qualities, $F(q)=1-q^{-\theta}$.

An idea applies to only one out of the continuum of inputs. The input $j$ to which the idea applies is drawn from the uniform distribution on $[0, J] .{ }^{10}$

Ideas, even good ideas, do not diffuse immediately. Let $\tau$ be the random diffusion lag. If an idea is discovered at time $t$ in country $i$ then it diffuses to country $n$ at time $t+\tau_{n i}$, for $n=1,2, \ldots, N$. We assume that the marginal distribution of the diffusion lag from country $i$ to country $n$ is exponential with parameter $\epsilon_{n i}$, i.e. $\operatorname{Pr}\left[\tau_{n i} \leq x\right]=1-e^{-\epsilon_{n i} x}$. Thus $\epsilon_{n i}$ is the speed of diffusion from country $i$ to country $n$ and $\epsilon_{n i}^{-1}$ is the mean diffusion lag.

We distinguish between the concepts of diffusion and adoption. While every idea will eventually diffuse to every other country (if the $\epsilon_{n i}$ 's are strictly positive) many ideas will never be adopted because they are not useful. Some ideas are not useful even when they are invented while other ideas are no longer useful by the time they have diffused.

\footnotetext{
'Bental and Peled (1992) and Kortum (1894) also use the Pareto distribution to characlerize the pool of undiscovered techniques from which researchers draw. The Pareto distribution has the convenient feature that, if we truncate the distribution at some level $z$, then the random variable $Q / z(\geq 1)$ inherits the $P$ areto distribution. Thus, if a new idea is better than current best practice (say z) then the distribution of the inventive step $(Q / 2)$ does not depend on the level of the best practice that is surpassed.
}

${ }^{10}$ We ienore the possibility that research could be aimed at improving tbe quality of apecific input. 


\subsection{The Technological Frontier}

In equilibrium, only the best available idea for each input in each country is actually adopted. Thus for each country $n, Z_{n t}(j)$ represents the highest quality idea yet adopted in country $n$ in sector $j$ by time $t$, so that $\left\{Z_{n t}(j)\right\}_{j \in[0, \eta]}$ is the technological frontier in country $n$ at time t. Consider an idea of quality $q$ in sector $j$ discovered somewhere at time $t$. If the idea diffuses to country $n$ with a lag of $\tau$ then it will constitute an innovation if and only if $q>Z_{n t+\tau}(j)$. In this case the idea is adopted so that the technological frontier at $j$ jumps discontinuously from $Z_{n t+\tau}(j)$ to $q$.

To derive the dynamics of the technological frontier in a given country, we need to know the rate at which ideas were discovered in all countries over all of history. Researchers in country $n$ produce new ideas at a nonstochastic rate $\alpha_{n t} L_{n t}^{1-\beta} R_{n t}^{\beta}$. Let $\dot{\mu}_{n t}$ be the stochastic rate at which ideas of a given sector diffuse to country $n$ from all the research that has been done throughout the world. (The corresponding stock is $\mu_{n t}=\int_{-\infty}^{t} \dot{\mu}_{n s} d s$.) An idea may be the result of domestic research or may arrive from some other country. It may be the outcome of research performed recently or years before. Integrating over the appropriately weighted past research done in country $i$ the stock of ideas flowing into country $n$ 's technology is, summing across countrięs,

$$
\dot{\mu}_{n t}=J^{-1} \sum_{i=1}^{N} \epsilon_{n i} \int_{-\infty}^{t} e^{-\epsilon_{n i}(t-s)} \alpha_{i \rho} L_{i \rho}^{1-\beta} R_{i \rho}^{\beta} d s .
$$

Let $z$ denote the level of the technological frontier in a particular sector of country $n$. 
Letting $H_{n}(z \mid t) \equiv \operatorname{Pr}\left[Z_{n t}(j) \leq z\right]$, the distribution of this frontier is: ${ }^{11}$

$$
H_{n}(z \mid t)=e^{-\mu_{n+2} z^{-0}}
$$

Note that the distribution of the technological frontier depends only on the total stock of ideas $\mu_{n t}$ at that time, regardless of when these ideas were adopted for production or where they came from. This feature of the distribution simplifies the analysis drastically.

\subsection{Productivity}

Output is maximized when production workers are evenly divided among production of the individual inputs. In this case labor productivity is the geometric mean of tie technological frontier. Thus, we use $A_{n t}$ defined by,

$$
\ln A_{n t}=J^{-1} \int_{0}^{J} \ln Z_{n t}(j) d j
$$

as an index of productivity in country n. ${ }^{12}$ Using our result on the distribution of the technological frontier, we have,

$$
\ln A_{n t}=\int_{1}^{\infty} \ln z h_{n}(z \mid t) d z
$$

\footnotetext{
${ }^{11}$ Ideas are adopted in sector $z$ at a stochastic rate of $\dot{\mu}_{n t}{ }^{-\theta}$. The probability that no viea is adoptod in the time interval $[t, t+d t]$ is thus $e^{-\dot{\mu}_{n 1} t^{-*} d t}$. Therefore,

$$
H_{n}(z \mid t+d t)=H_{n}(z \mid t) e^{-\dot{H_{n} z^{-0}} \alpha t}
$$

or.

$$
\frac{\partial \ln H_{n}(z \mid t)}{\partial t}=-\dot{\mu}_{n t} z^{-\bullet}
$$

Solving this differential equation, with the two initial conditions: (i) lim, $--\infty H_{n}(z \mid s)=1 \forall z \geq 1$ and (ii) $\lim _{0 \rightarrow-\infty} \mu_{n}=0$, yields the cumulative distribution function for the technological frontier.

${ }^{12}$ The market structure that we asume does not, in fact, imply an even allocation of production workers among inputs, since the mark-up differs waras sectore. Productivity is proportional to this index, however, w can be aen from equation (10) and (11) below.
} 
where $h_{n}(z \mid t)=\frac{d H_{n}(z \mid t)}{d z}=\theta \mu_{n t} z^{-(\theta+1)} e^{-\mu_{n t} z^{-0}}$. Solving this integral, as $\mu_{n t}$ becomes large, we obtain:

$$
A_{n t}=e^{\psi / \theta} \mu_{n t}^{1 / \theta},
$$

where, $\psi \approx .5772$ is Euler's constant. ${ }^{13}$ Thus productivity growth in a country is proportional to the growth in the stock of ideas that have diffused to that country. ${ }^{14}$

${ }^{13}$ Changing the variable of integration to $x=\mu_{n+z^{-0}}$,

$$
\ln A_{n t}=\theta^{-1} \int_{0}^{\mu_{n t}} \ln \left(\mu_{n t} / x\right) e^{-\approx} d x=\theta^{-1} \ln \mu_{n t}\left(1-e^{-\mu_{n 1}}\right)-\theta^{-1} \int_{0}^{\mu_{n 1}} \ln x e^{-x} d x .
$$

For large $\mu_{n t}$ we have an arbitrarily good approcimation,

$$
\ln A_{n t}=\theta^{-1} \ln \mu_{n t}-\theta^{-1} \int_{0}^{\infty} \ln x e^{-\infty} d x \text {. }
$$

The Laplace transform of $-\psi-\ln t$ is $s^{-1} \ln s$, where $\psi$ is Euler's constant. Evaluating the Laplace transform at $s=1$ implies,

$$
\int_{0}^{\infty} \ln x e^{-x} d x=-\psi
$$

This gives us the desired result that,

$$
\ln A_{n t}=\theta^{-1} \ln \mu_{n t}+\psi / \theta
$$

${ }^{14}$ As we discussed in our introduction, our model implies that an ides is more likely to be adopted in a country with a relatively low level of productivity. The probability that an ides of quality $q$ will prove useful is simply $H_{n}(q \mid t)$. Integrating this probability over the Pareto density of $Q$, and noting that $\mu_{n z}$ becomes arbitrarily large over time, we get

$$
\int_{1}^{\infty} H_{n}(q \mid t) F^{\prime}(q) d q=\int_{1}^{\infty} \theta q^{-(0+1)} e^{-\mu_{n 1} q^{-\theta}} d q=\mu_{n t}^{-1}=e^{\psi} A_{n t}^{-\theta} .
$$

Consider two countries, $m$ and $n$, with levels of productivity $A_{m t}$ and $A_{n t}$ respectively. The probsbility that an idea will be adopted in country $m$ relative to the probability that it will be adopted in country $n$ is simply, $\left(A_{m t} / A_{n t}\right)^{-\bullet}$. Thus if $A_{m t}<A_{n t}$, country $m$ will obtain more true innovation than will country $n$ from the same number of ideas. In this senoe the low productivity country drawa innovations from the "technolosy gap". 


\subsection{Market Structure}

We assume that the right to use an invention in country $n$ passes to a local, monopolistic imitator with a hazard that depends on whether or not the inventor has a patent in that country. We denote the hazard of imitation if the invention was patented as $\iota_{n}^{\text {pat }}$ and if it was not patented as $\iota_{n}^{\text {not }}$. For a patent to. have any value requires, of course, that $\iota_{n}^{\text {pat }}<\iota_{n}^{\text {not }}$. If patents provide perfect protection then $\iota_{n}^{\text {pat }}=0$, while if trade secrets are impossible to keep then $\iota_{n}^{\text {not }}=\infty .^{15}$

Whether the rights to the invention are owned by the original inventor or by an imitator, the owner competes against the state of the art for that input in that country at the time of invention. We assume that competition is Bertrand. Hence the owner of the invention charges the highest price at which production using the previous state of the art is ti:-profitable. ${ }^{16}$

\footnotetext{
${ }^{15}$ We do not allow the inventor to wait until the invention is adopted in a country to apply for a patent there. This assumption reflects the requirement of most patent systems that patents be taken out in additional countries within one year of the first, or priority, application. We ansume that inventors do not delay sockins a priority application.

${ }^{16} \mathrm{Grossman}$ and Helpman (1991) make similar assumptions. The production tochnology implies a unit elastic demand for an individual input given the prices of all other inputs. Hence to mwimize profit the owner of the invention charges the highest price at which it remains the only seller of that input. We asoume that the owner of the right to use the invention, when the invention is adopled in a country, competes with the state of the art at the time of invention. The owner of an invention thus blocks protoction of any interim improvement over the initial state of the art that is dominated by that invention. This asumption is consistent with the requirement of most patent syatems that onby ideas that are "state of the art," can roceive protoction, where state of the art" is interpreted to mean the most advanced idea regardleas of whether or not it has been adoptod for production. This assumption is easier to justify when the original inventor holds a patent than when a domestic imitator owns the right to the invention. The alternative assumptions that an imitator competes against the next-best adopled technolosy, or that imitation in perfoctly competitive, both imply lower mark-upe over direct production costs for unpatented inventions. While this implication may be realistic, the conseguent asymmetry in mark-ups between patented and imitated inputs subetentially complicates the analyais. Moreover, it implies that the patent system itself has real effects on productivity conditional on the level of research. To focus
} 


\subsection{The Value of an Invention}

Our assumptions about price competition imply that a firm producing an input of quality $q$ in a country where the state of the art for that input at the time of discovery was $z$ will charge $p=(q / z) w$, where $w$ is the wage in the country at the time. We use the price of final output

as numeraire. Total purchases of the new input are $\frac{Y}{J_{p}}$. Given the pricing equilibrium, the profit to the owner of the right to use a technology of quality $q$ improving on an existing input of quality $z$ is $\pi(z, q)=\left(1-\frac{z}{q}\right) \frac{Y}{J}$ if $q>z$ and zero otherwise.

The owner can earn a profit only after the invention has been adopted and only before it has been surpassed by a more advanced technology. Consider, then, the expected profit in country $n$ at time $s$ from an invention of quality $q$ at time $t<s$ in country $i$. The probability of its having been adopted for production by time $s$ is $\left(1-e^{-\epsilon_{n i}(a-t)}\right)$. The probability of its not having become obsolete by then is $e^{-\left(\mu_{n}-\mu_{n t}\right) q^{-\infty}}$, while the probability if its not having been copied by then is $e^{-t_{n}^{h}(s-t)}$, where $k \in\{$ pat, not $\}$ depending upon whether or not the invention was patented. At the time $t$ that an invention of quality $q$ occurs in country $i$, the expected discounted value of the right to use it in country $n$, given the existing state of the art $z$ in the relevant sector, is therefore:

$$
V_{n i t}^{k}(z, q)=\int_{0}^{\infty} \pi_{n t+o}(z, q) e^{-\left(r+\iota_{n}^{k}\right) \cdot}\left(1-e^{\left.-\varepsilon_{n i}\right)}\right) e^{-\left[\mu_{n t+o}-\mu_{n t} \mid q^{-} \cdot\right.} d s
$$

if $q \geq z$. Otherwise the value is zero. Here again $k=$ pat if the idea was patented and $k=$ not otherwise, and $r$ is the discount rate, which we treat as constant over time.

\subsection{The Decision to Patent}

A patent gives the inventor the incremental benefit of a lower hazard of imitation, so is worth $V_{\text {nit }}^{\text {pat }}(z, q)-V_{\text {nit }}^{\text {not }}(z, q)$. We assume that, at the time of invention, the researcher knows the on other implications of the international patent nyatem more critical to the anabysis bere we proclude this possibility. 
quality of the invention but not the state of the art in the sector to which it will apply in each country. Integrating over the distribution of the states of the art in country $n$, given by equation (2), the expected value of an idea of quality $q$ from country $i$ in country $n$ is:

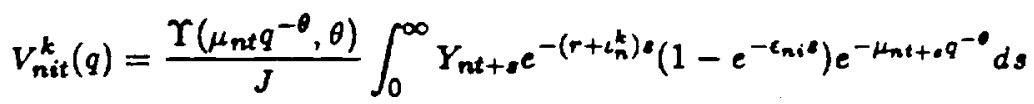

where, $k=$ pat, not depending upon whether or not the ides is patented and $\Upsilon(b, \theta) \equiv 1-$ $e^{b} b^{1 / \theta} \Gamma\left(\frac{\theta-1}{\theta}, b\right)$, where $\Gamma(a, b) \equiv \int_{b}^{\infty} e^{-x} x^{a-1} d x$ is the incomplete gamms function. Hence, if it costs an inventor in country $i c_{n i t}$ to patent in country $n$ then the inventor will seek patent protection in that country if $V_{\text {nit }}^{\text {pat }}(q)-V_{\text {nit }}^{\text {not }}(q)$ exceeds $c_{\text {nit }}$ and not otherwise. The return to patenting rises with the quality of the invention $q$. Hence the condition:

$$
V_{\text {nit }}^{\text {pat }}(q)-V_{\text {nit }}^{\text {not }}(q)=c_{\text {nit }}
$$

determines a threshold quality level $\bar{q}_{\text {nit }}$ such that inventions of higher qual: $\longleftarrow$ v are patented while those of lower quality are not. ${ }^{17}$ We assume that if an invention constitutes an innovation in a country then a patent is automatically granted.

Since researchers in country $i$ produce ideas at rate $\alpha_{i t} L_{i t}^{1-\beta} R_{i t}^{\mathcal{\beta}}$, the number of patents they apply for in country $n, P_{\text {nit }}$ is:

$$
P_{n i t}=\alpha_{i t} L_{i t}^{1-\beta} R_{i t}^{\beta} \bar{q}_{n i t}^{-\theta} .
$$

Since the fraction of ideas seeking protection is $\bar{q}_{n i t}^{-\theta}$, while the fraction that are potentially useful is $\mu_{n t}^{-1}$, the ratio of the number of patented to potentially useful ideas is:

$$
\bar{b}_{n i t} \equiv \mu_{n t} \bar{q}_{n i t}^{-\theta} .
$$

As we show below, in steady state this ratio is constant.

\footnotetext{
${ }^{17} \mathrm{~A}$ poesibility, of course, is that the cost of patenting would excoed the benefit for any invention regardless of its quality, in which case patenting would be zero, and $\bar{g}_{n \text { it }}$ infinite. At the other extreme, if $c_{n i t}=0$ then $\bar{q}_{n i t}=1$, so that any idea would be patented.
} 


\subsection{The Return to R\&D}

The value of an invention of quality $q$ from country $i$ in country $n$ is the maximum of $V_{n i t}^{\text {pat }}(q)-$ $c_{\text {nit }}$ and $V_{\text {nit }}^{\text {not }}(q)$. The expected value of an idea in that country before its quality is known is therefore the expectation of this amount across all possible values of $q$, which is:

$$
V_{n i t}=\int_{1}^{\varphi_{n i t}} V_{n i t}^{n o t}(q) F^{\prime}(q) d q+\int_{\bar{q}_{n i t}}^{\infty} V_{n i t}^{\text {pat }}(q) F^{\prime}(q) d q-c_{n i t} \bar{q}_{n i t}^{-\theta}
$$

where, as before, $F^{\prime}(q)=\theta q^{-(\theta+1)}$ is the Pareto density. The expected return to an idea of unknown quality in country $i$ at time $t$ is therefore the sum of its expected returns across countries, or

$$
V_{i t}=\sum_{n=1}^{N} V_{n i t} .
$$

This amount represents the expected return to 8 unit of R\&D effort.

\subsection{Equilibrium R\&D}

The marginal researcher in country $i$, ranked $R_{i}$, can expect to earn $\alpha_{i t} \beta V_{i t}\left(\frac{R_{i}}{L_{i t}}\right)^{\beta-1}$ doing research. Equilibrium in the labor market thus implies that the number of researchers $R_{i t}$ in country $i$ will solve:

$$
\alpha_{i t} \beta V_{i t}\left(\frac{R_{i t}}{L_{i t}}\right)^{\beta-1}=w_{i t},
$$

where $w_{i t}$ is what a marginal researcher would earn producing output.

\subsection{Technology, Wages, and Income}

The wage in the production sector of country $i$ is proportional to the level of productivity in that country. Bertrand competition implies that the mark-up over this wage, $M(j) \equiv$ $p(j) / w$, is low in sectors where the currently adopted input is only marginally better than the input it replaced while $M(j)$ is large in those sectors where the current input is a substantial improvement over its predecessor. Since expenditure on each input is the same, more labor 
is allocated to the production of inputs with low mark-ups. Consequently, the wage, as well as productivity, is lower than would be the case if production workers were equally allocated among sectors. As we show in the appendix, the mark-up $M$ is a random variable with a time-invariant distribution with density:

$$
g(m ; \theta) \equiv \frac{\theta m^{-1}}{m^{\theta}-1}\left(\frac{\theta m^{\theta}}{m^{\theta}-1} \ln m-1\right) .
$$

Given this density and the level of productivity, the wage is:

$$
w_{i t}=e^{-\kappa_{1}(\theta)} A_{i t}
$$

where,

$$
\kappa_{1}(\theta) \equiv \int_{1}^{\infty} \ln m g(m ; \theta) d m
$$

The value of total output equals wage costs plus profits. Again, taking into account the distribution of the mark-up, the value of output in country $i$, given the wage and the labor force in production there, is:

$$
Y_{i t}=\frac{w_{i t}}{\kappa_{2}(\theta)}\left(L_{i t}-R_{i t}\right)
$$

where

$$
\kappa_{2}(\theta) \equiv \int_{1}^{\infty} m^{-1} g(m ; \theta) d m
$$

The appendix provides the derivation of the expressions for $g(m ; \theta)$, the wage, and the value of output.

We have now fully specified our model. To summarize, equation (1) relates R\&D effort to subsequent growth of technology in different countries. Equation (4) determines what ideas are patented given the value of output. Equations (7), (8), and (9) determine the division of the labor force in a country between production and research and development as a function of the wage in that country and output levels around the world. Finally, equation (10) relates 
the wage in a country to its level of technology while equation (11) relates a country's output to jts level of technology and the size of its labor force engaged in production.

We treat the total labor force in each country as exogenous. The state of the economy at any moment can be described in terms of the $N$ technology parameters $\mu_{n}$ which evolve according to (1). The economy is in equilibrium when, taking as given the current and future state of the economy, patenting and labor allocation decisions are individually optimal, as implied by (4) and (9).

\section{The Steady State}

The economy is in steady state when the state variables $\mu$ grow at a constant common rate, which we denote $g$, and patenting is constant. In order to obtain a steady-state outcome we make the following assumptions about exogenous variables:

(i) Total labor forces in each country are constant. Hence $L_{n t}=L_{n} \forall t$.

(ii) The productivity of researchers is proportional to the current level of technology where they work, so that the number of new ideas generated by a given research effort is proportional to the stock of existing ideas. ${ }^{18}$ Specifically, we assume that $\alpha_{i t}=\alpha \mu_{i t}$.

(iii) Patenting costs are a constant proportion of output, that is $c_{n i t}=c_{n i} Y_{n t}{ }^{19}$

\footnotetext{
${ }^{18}$ An equivalent assumption is made in many other models of endogenous growth, as, for example, in Krugman (1979) and in Grossman and Helpman (1991). With constant labor forces this assumption is needed for the economy to grow in steady state. Technologies and ideas would also grow if labor forces grew at a constant poeitive rate $n$ and research productivity were given by $a_{t t}=a \mu \mu_{i t}^{7}, \gamma \in[0,1)$. Ideas and technology would then grow at rate $n /(1-\gamma)$. Kortum (1994) develope a model with these fentures (with $\gamma=0$ ) for a closed economy. ${ }^{19}$ This assumption is equivalent to asouming that examining a patent requires a constant labor input whose coat in pased on to the applicant. If productivity growth were reflected in lower patenting conts, eventually all new ideas, no matter bow bad, would be patented. Since we obeerve a rate of domestic patenting that is not growing over time (with the exception of Japan), we find it reasonable to aserume that patenting costs have not been falling relative to market size.
} 
Two features of a steady state are: (i) a constant number $R_{i}$ of workers in each country engaged as researchers; and (ii) patenting thresholds that are proportional to the destination country's productivity, i.e, constant values of $\bar{b}_{n i}$ as defined by equation (6).

From equation (1), given the constant number of researchers $R_{i}$ and labor force $L_{i}$ in each country, the steady-state growth rate of technology and the steady-state relative technology levels solve the system of $N$ equations:

$$
\mu g=\Delta(g) \mu
$$

where $\mu \equiv\left(\mu_{1 t} / \mu_{N t}, \ldots, \mu_{N-1 t} / \mu_{N t}, 1\right)^{\prime}$ and

$$
\Delta(g)=\left[\begin{array}{ccc}
\delta_{11} & \ldots & \delta_{1 N} \\
\vdots & \ddots & \vdots \\
\delta_{N 1} & \ldots & \delta_{N N}
\end{array}\right]
$$

where:

$$
\delta_{n i} \equiv \frac{\epsilon_{n i}}{\epsilon_{n i}+g} \frac{\alpha}{J} R_{i}^{\beta} L_{i}^{1-\beta}
$$

The solution to this system gives the world rate of productivity growth, $\dot{A} / A=g / \theta$ and relative productivity levels,

$$
\frac{A_{n t}}{A_{N t}}=\left(\frac{\mu_{n t}}{\mu_{N t}}\right)^{1 / \theta}, n=1, \ldots, N-1
$$

From equation (4), given the growth rate $g$, patenting thresholds $\bar{b}_{n i}=\mu_{n t} \bar{q}_{n i t}^{-\theta}$ are determined by the $N^{2}$ equations:

$$
\begin{aligned}
\frac{\Upsilon(\bar{b}, \theta)}{J g} & \left\{\Psi\left(\hat{r}_{n}^{\text {pat }} / g, \bar{b}\right)-\Psi\left(\left(\hat{r}_{n}^{\text {pat }}+\epsilon_{n i}\right) / g, \bar{b}\right)\right]- \\
& {\left.\left[\Psi\left(\hat{r}_{n}^{\text {not }} / g, \bar{b}\right)-\Psi\left(\left(\hat{r}_{n}^{\text {not }}+\epsilon_{n i}\right) / g, \bar{b}\right)\right]\right\}=c_{n i}, }
\end{aligned}
$$

where:

$$
\hat{r}_{n}^{k} \equiv r+\iota_{n}^{k}-\frac{g}{\theta} \quad k=p a t, n o t
$$


and $\Psi(a / g, b) \equiv g \int_{0}^{\infty} e^{-a s} e^{-b e j e} d s .^{20}$ Note that the only country characteristics that directly affect the patenting threshold are the adoption lag $\epsilon_{n i}$, the strength of patent protection rates as reflected by $\iota_{n}^{\text {pat }}$ and $\iota_{n}^{\text {not }}$, and the cost of patenting $c_{n i}$. In particular, $\bar{b}_{n i}$ does not depend on the levels of technology $\mu_{n t}$ and $\mu_{\text {it }}$.

In steady state, the expected value of an idea of unknown quality from country $i$ in country $n, V_{n i t}$, will be a constant proportion $v_{n i}$ of country $n$ 's output $Y_{n t}$ divided by its level of technology $\mu_{n t}$, that is,

$$
V_{n i t}=v_{n i} Y_{n t} \mu_{n t}^{-1}
$$

where:

$$
\begin{gathered}
v_{n i} \equiv(J g)^{-1}\left\{\int_{0}^{\delta_{n i}} \Upsilon(b, \theta)\left[\Psi\left(\tilde{r}_{n}^{\text {pat }} / g, b\right)-\Psi\left(\left(\tilde{r}_{n}^{\text {pat }}+\epsilon_{n i}\right) / g, b\right)\right] d b\right. \\
\left.+\int_{\bar{b}_{n i}}^{\infty} \Upsilon(b, \theta)\left[\Psi\left(\tilde{r}_{n}^{n o t} / g, b\right)-\Psi\left(\left(\tilde{r}_{n}^{n o t}+\epsilon_{n i}\right) / g, b\right)\right] d b\right\}-c_{n i} \bar{b}_{n i}
\end{gathered}
$$

where:

$$
\tilde{r}_{n}^{k} \equiv \hat{r}_{n}^{j}+g \quad k=\text { pat, not }
$$

As is the case with $\bar{b}_{n i}, v_{n i}$ depends on the adoption lag, the strength of intellectual property protection, and the cost of patenting, but not on technology levels. The steady-state return to doing research to the $R_{i}$ th researcher in country $i$ is thus:

$$
\alpha \beta\left(\frac{R_{i}}{L_{i}}\right)^{\beta-1} \sum_{n=1}^{N} v_{n i} Y_{n t} \frac{\mu_{i t}}{\mu_{n t}}
$$

while the return to producing output is simply $w_{i t}$.

\footnotetext{
${ }^{20}$ In order to compute thin Integal, we rely on the result that for $b>0$,

$$
\Psi(a / g, b)=b^{-/ *} \Gamma(-a / g, b)
$$

As a consequence, we also have

$$
\Upsilon(b, \theta)=1-b e^{\theta} \Psi\left(\frac{1-\theta}{\theta}, b\right)
$$

There is a continued fraction representation for the incomplete gamma function (that admits $d<0$ ) leading to a speedy numerical algorithm [from Pres et. al. (1989), pp. 160-163].
} 
Substituting equations (10) and (11), the condition for steady-state labor market equilibrium in each country, from (9), becomes: ${ }^{21}$

$$
\alpha \beta\left(\frac{R_{i}}{L_{i}}\right)^{\beta-1} \sum_{n=1}^{N} v_{n i}\left(L_{n}-R_{n}\right)\left(\frac{\mu_{n}}{\mu_{i}}\right)^{(1-\theta) / \theta}=\kappa_{2}(\theta) .
$$

To summarize, the $N(N+2)$ equations (12), (13) and (14) determine the steady-state growth rate $g, N-1$ relative technology levels $\mu, N^{2}$ patenting thresholds $\bar{b}$, and $N$ levels of R\&D, $R$. Given, $R,(12)$ determines $g$ and $\mu$. Given $g$, (13) determines $\bar{b}$. Given $g, \bar{b}$, and $\mu,(14)$ determines $R$.

How much patenting is done in steady state? Substituting the relevant steady-state magnitudes into equation (5) implies that the steady-state number of patents applied for by inventors from country $i$ in country $n$ is:

$$
P_{n i}=\alpha R_{i}^{\beta} L_{i}^{1-\beta} \frac{\mu_{i}}{\mu_{n}} \bar{b}_{n i}
$$

As technology advances researchers become more productive, so more ideas are produced. But as technology advances a smaller percentage of these new ideas constitute improvements in the state of the art, so are worth patenting. In steady state these two effects cancel out, yielding a constant rate of patenting.

\section{Calibration}

We assume that the steady state of our model describes, in 1988 , world prociuctivity growth, relative levels of productivity, numbers of researchers, and foreign and domestic patenting

\footnotetext{
${ }^{21}$ Since $v_{n i}$ is independent of tochnology levels, an implication of this expression is that the elasticity of R\&D with respect to the level of technology has the sign of $1-6$. Researchers in countries with more advancod technologies, as measured by $\mu$, are proportionately more productive as researchers, but their opportunity cost of doing research in also greater in proportion to $\mu^{t}$. The net effect is more research in advancod countries if $\theta$ exceeds one and less otherwise.
} 
among Germany, France, the United Kingdom, Japan and the United States. ${ }^{22}$ In this section we let the data from these economies determine a vector of parameters, including diffusion parameters, for our theoretical model.

\subsection{Solving the Model}

The steady-state equations of the model can be represented as

$$
y=G(\theta, x)
$$

where $y$ is a vector of observable endogenous variables, $\theta$ is a vector of parameters, and $x$ is a vector of exogenous variables. The function $G($.$) represents the simultaneous solution of$ equations (12), (13), and (14) as well as the productivity and patenting equations: (3) and (15).

We assume that all patent systems are the same, but allow them to provide different degrees of protection to nationals than to foreigners. Hence we define $i_{D}^{\text {pat }}$ as the imitation rate when an invention is patented domestically and $\iota_{F}^{\text {pat }}$ as the imitation rate when an invention is patented abroad. The hazard of imitation of unpatented inventions $\iota^{\text {not }}$ is the same everywhere.

We assume that the rate of diffusion of inventions from country $i$ to country $n$ is the product of a parameter governing the speed at which county $n$ adopts new inventions, a parameter governing the speed at which inventions from country $i$ are ready for adoption, and a parameter governing the percentage increase in adoption speed for domestic inventions. Formally, $\epsilon_{n i}=\epsilon_{n} \epsilon_{. i} \epsilon_{D}$, where we normalize $\epsilon_{5 .}=1$ and $\epsilon_{D}=1$ if $n \neq i$. Thi's we require ten parameters to account for the 25 diffusion rates between and within our five countries.

\footnotetext{
${ }^{22}$ We have chosen these five countriea becauve of their aize and research intensity: together they employ over 80 percent of the world's research scientiats and enpinoers. Furthermore, each of these five countries obtains between $70 \%$ and $80 \%$ of it foreign patent application from one of the other four. About $60 \%$ of the world's Gros Domestic Product (GDP) is produced in these countries (Summers and Heston (1991)). Hence our five countries account for most of the world's inventive activity and a majority of the market for inventions.
} 
In summary, we search for 17 parameters

$$
\theta \equiv\left[r, \theta, \beta, J, \alpha, \iota^{\text {not }}, \iota_{D}^{\text {pat }}, \iota_{F}^{\text {pat }}, \epsilon_{.1}, \ldots, \epsilon .5, \epsilon_{1,}, \ldots, \epsilon_{4 .}, \epsilon_{D}\right]^{\prime}
$$

The values of the exogenous variables,

$$
x \equiv\left[L_{1}, \ldots, L_{5}, c_{11}, \ldots, c_{n i}, \ldots, c_{55}\right]^{\prime}
$$

are shown in table 1. The workforce in each country $L_{i}$ is taken from Summers and Heston (1991). The patenting costs are based on country specific filing fees, agents fees, and translation costs taken from Helfgott (1993). ${ }^{23}$ To obtain the $c_{n i}$ we divide the application costs by the adjusted GDP of the country charging the application fee. ${ }^{24}$ We fix the interest rate at $7 \%$ based on historical real returns on the U.S. stock market.

There are 35 endogenous variables in the model,

$$
y \equiv\left[\dot{A} / A, A_{1 t} / A_{5 t}, \ldots, A_{4 t} / A_{5 t}, R_{1}, \ldots, R_{5}, P_{11}, \ldots, P_{n i}, \ldots, P_{55}\right]^{\prime}
$$

as shown in table 2.

\footnotetext{
${ }^{23}$ These costs were adjusted for Japanese domestic applications. The Japanese apply for over 300,000 patents domestically each year. Olads (1992) finds that Japanese patents granted to foreigners contain on average 4.9 times as many inventive claims as those granted to Japanese inventors. Thus we translate 4.9 Japasese domestic patent applications into the equivalent of 1 application elsewhere. This adjustment is reflectod in table 2 . We also scale up the cost of an application for a Japanese inventor in Japan by this same factor of 4.9. We ignore the more complicated foe structure applying to patents through the Europesn Patent Office and complications introduced by patent renewal feea.

${ }^{24}$ Helfgott collected the coet of application data from a eurvey in 1992 and convertod all the figures into SU.S. using the exchange rate in effoct "near the end of 1992". We took 1992 GDP in local currencies from IMF (1994). We then converted GDP into sU.S. uring 1992 fourth quarter exchange rates from IMF (1994) and we subtractod from GDP the whare of GDP spent on R\&D, from OECD (1901). Since we ignore patent renewal foes and the possible cost of dieclosure of information in taking out a patent, our measure of the cost of patenting is a bower bound on the true costs. To chock the sensitivity of results to substantially higher application costs we experimented with increasing all foreign patenting costs by $\$ 10,000$. There were no substantialty different implications for diffusion.
} 


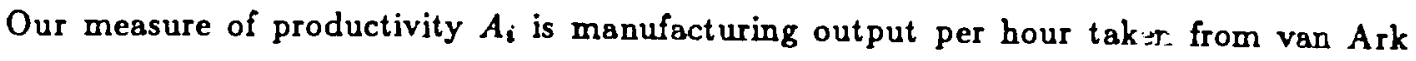
and Pilat (1993). We calculate productivity growth by averaging over our five countries from 1979-1989. We use manufacturing productivity to represent a country's overall technological capability since productivity may be poorly measured in other sectors.

To measure research effort $R_{i}$ we use research and development scientists and engineers employed by the business sector in each country in 1988. To eliminate the effect of defense related research we multiply these employment numbers by the fraction of business sector $R \& D$ financed by either the business sector or from abroad. All data on research are from OECD (1991).

Patent applications by country of application and resident of inventor in $1988\left(P_{n i}\right)$ are from WIPO (1990). As mentioned in the footnote above, patent applications in Japan by Japanese inventors have been scaled down by a factor of 4.9. Since patent law requires that an inventor apply for a patent in any other country within a year of the first (or priority) application, patent applications rather than grants capture better the inventor's patenting decision in our model. Moreover, applications rather than grants are much more comparable across countries.

In order to evaluate the plausibility of a given parameter vector $\hat{\theta}$, we need to compare the predictions of the model, $\hat{y}=G(\hat{\theta}, x)$, with the actual value of the endogenous variable, $y$. We have written a computer algorithm to do this. ${ }^{25}$

\footnotetext{
${ }^{28}$ We solve the model using GAUSS. The program begins with a parameter voctor and a guese for the the srowth rate of technology, $g$. Then, (i) it finds the set of $b_{n i}$ that solve equation (13); (ii) it iterates between equations (12) and (14) until it finds technology levels and research employments that are ronsistent with each other; (iii) it uees (12) to obtain a new value for the erowth of technolosy; (iv) with the new value of $g$ it returne to the beginning of step (i). These stepe are repented until the growth of technology stope changing. Finally, equations (3) and (15) are used to infer productivity and patenting. The entire process takes about 1 minute on a Pentium PC.
} 


\subsection{Baseline Parameters}

We choose baseline parameters to match the steady-state values of the variables implied by the model as closely as possible to our measures of the endogenous variables. Hence we minimize the distance function, $\sum_{j=1}^{38} \delta_{j}\left(\frac{\hat{i}_{j}-y_{j}}{y_{j}}\right)^{2}$, where $\delta_{j}$ is the weight placed on variable $j$. Our thirtyfive endogenous variables consist of five productivity variables (four relative productivities and productivity growth), research scientists and engineers in the five countries, and twenty-five patent levels between countries. In order to give each type of variable equal weight we choose $\delta_{j}=1$ for $j=1, \ldots, 10$ and $\delta_{j}=1 / 5$ for $j=11, \ldots, 35 .^{26}$

The parameters that fit best are shown in table 3 . Our estimate of $\theta$ is somewhat above one, implying that, other things equal, the return to research relative to production is greater in more advanced countries. We obtain a very small value for the parameter $\beta$ of the distribution of research talent. This result suggests that research output is roughly proportional to the workforce in each country with only a small effect from the fraction of the workforce engaged in research. While we find that domestic patents virtually preclude imitation, foreiga patents provide very little protection. This reflects the fact that the home country is always the most popular country in which to seek protection (by at least a factor of 2, table 2). Our imitation rates are lower than those reported by Levin et. al. (1987), although their concept of imitation seems to encompass our notion of obsolescence as well.

Turning to diffusion rates, we find them to be considerably more rapid within than between countries. For example, the rate of domestic diffusion in the United States is 0.03 , while from the United States to Japan it is $\mathbf{0 . 0 0 3}$. For inventions from Japan, the rate of domestic difusion is 0.17 while the rate of diffusion to the United States is 0.02 . Though the implied mean diffusion lags are large, they are consistent with the results of micro y onomic studies

\footnotetext{
${ }^{25}$ To calculale baseline parameters we nested our algorithm for solving the steady state of our model for a given parameter vector within a otanderd minimization routine. Using the AMOEBA non derivative routine minimization took several days on a Pentium PC.
} 
summarized in Jovanovic and Lach (1993). ${ }^{27}$

Table 4 shows how the model performs at fitting the vector of endogenous variables. The model is highly successful at fitting overall productivity growth, relative productivity levels, and levels of research employment in each country. Patterns of international patenting are less successfully captured though the overall level of patenting is about right.

\section{Decompositions and Counterfactuals}

Our estimates allow us to decompose the sources of growth in each country into what originates from domestic research and what originates from research in each of the other four countries. We also decompose the return to invention in each country into what is earned from the home market and from each of the other four. We then examine the implications of different amounts of international diffusion, and of different levels of intellectual property protection.

\subsection{The Sources of Growth}

Through the process of international technology diffusion, research done in one country leads to productivity growth elsewhere. Table 5 quantifies these links between countries. The European countries derive most of their growth from abroad while the United States and Japan obtain slightly more from domestic research. Japan, Germany, and the United States make the largest contributions to growth. A surprising result is that Germany and Japan each contribute more than the United States. Though the United States produces many more inventions, we find that these inventions diffuse quite slowly.

\footnotetext{
${ }^{27}$ Jovanovic and Lach's concept of the diffusion rate is the rate at which the market for a product reaches its potential. Our concept is the hazard rate until a product in adopted.
} 


\subsection{The Rewards to Research}

While the growth decomposition in table 5 looks at foreign countries as sources of new technology, table 6 looks at foreign countries as markets for new technology. We calculate the fraction of the average value of an invention arising from markets in each of the 5 courtries. Inventions obtain almost all their value domestically, even for the smaller European economies.

\subsection{Alternative Patterns of Diffusion}

Another way to quantify the role of international technology diffusion is to ask how the steady state of the model would differ if technological links between countries were reduced. The results of several such experiments are shown in table 7. For comparison, we repeat the predictions of the model from table 4 under the column "Baseline." Our first experiment, "Technological jsolation", reduces to 0.0001 the rate of diffusion between the United States and the block of four other countries. Since the block of four other countries grows faster on its own than does the United States, the U.S. level of productivity must fall relative to the other countries (by a factor of more than 10) before the resulting technology gap supports the new steady state growth rate. ${ }^{28}$ The new growth rate is about 90 per cent of the baseline value. Our second experiment, "Borderless diffusion" eliminates the effect of country borders on diffusion rates. In particular, we set $\epsilon_{D}=9.77$ even if $n \neq i$. Since ideas now spread more rapidly and evenly across countries, the world growth rate rises and productivity levels becomes more tightly clustered around the U.S. level. Research employment is stimulated, particularly in the smaller countries (Germany, France, and the U.K.) which now have a much larger effective market for their inventions.

\footnotetext{
${ }^{20}$ Thus, in the new ateady atate the United States is not completely ieolated since it obtains many innovations from abroad, albeit years later.
} 


\subsection{The Strength of Patent Protection}

We conclude with some counterfactual experiments on the strength of patent protection. In the first experiment we eliminate all forms of patent protection by setting $\iota_{D}^{\text {pat }}$ and $\iota_{F}^{\text {pat }}$ equal to $\iota^{\text {not }}$, i.e., the hazard of imitation of patented ideas is as great as unpatented oner. With $\beta$ nearly zero, it is predictable that world productivity growth would not change drastically, although research employment falls considerably. The drop in research employment is particularly pronounced in Japan and the United States, which have large domestic markets. In the second experiment, we make patent protection perfect by setting $\iota_{D}^{\text {pat }}$ and $\iota_{F}^{\text {pat }}$ equal to zero, so that there is no hazard of imitation if an invention is patented. World productivity growth is higher by a modest factor of 1.003 , although research employment more than doubles. ${ }^{29}$

\section{Conclusion}

We have developed a model of the invention and the international diffusion of technology that allows us to identify the sources of growth and the sources of rewards to innovation in the world economy. While our model is complex, it nevertheless embodies several crucial simplifications.

First, we have ignored capital accumulation. We implicitly assume that capital is perfectly mobile among the countries we consider. An implication is that, while capital deepening and productivity growth are correlated, capital deepening is not the force driving growth. Capital moves endogenously to take advantage of technological improvement.

\footnotetext{
${ }^{29}$ These results should not be interpreted to mean that intelloctual property protection is undesirable. Present value calculations indicate that very mall changes in growth rates bave large effects on permanent income At the same time, since the number of research scientints and engincers in small relative to the total labor force, large percentage changes in reseanch employment imply very mall percentage changes in current output. For example, our calculations indicate that the magnitude of the steady-atate income gain due to higher growth from perfect patent protection is roughly comparable to the amount of ateady-atate income lost from diverting production workers to reacarch
} 
Second, we have ignored the terms of trade by treating intermediate inputs as nontraded. Changes in the terms of trade may be an important means by which the benefits of productivity growth diffuse internationally.

Finally, we have not examined the out-of-steady-state implications of our model. An outstanding question is whether convergence to the steady state of our model can explain the convergence of productivity levels exhibited by the countries in our sample auring the post World War II period. A puzzle posed by Jones (1993) is that the growth in research scientists and engineers during this period was accompanied by a falling rate of productivity growth. While there are many explanations for this finding, one that is consistent with our framework is that the research effort that accompanied World War II left the world with a pool of many good ideas. The subsequent absorption of these ideas into productive technology would then explain the exceptionally high growth rate in the two decades after the Second World War. We leave the examination of this hypothesis for future research.

We view our current work as only a first step in the empirical general equilibrium modeling of technology creation and diffusion in the world economy. While suggestive, our estimates should be interpreted with caution since we fit our model to a small amount of data from a small number of countries. Firm conclusions can only follow experimentation with alternative methodologies and richer data. Nonetheless, our analysis provides insights that are likely to survive further scrutiny. One broad conclusion is that technology among the major research economies diffuses much more slowly between countries than within them, yet even large countries derive a substantial share of their growth from abroad. 


\section{References}

Abramovitz, M. (1994), "Catch-Up and Convergence in the Postwar Growth Boom and After," in W.J. Baumol, R.R. Nelson, and E.N. Wolf, editors, Convergence of Productivity: Cross-country Studies and Historical Evidence. Oxford: Oxford University Press.

van Ark, B. and D. Pilat (1993), "Cross-Country Productivity Levels, Differences and Causes," University of Groningen.

Barro, R. J. and X. Sala-I-Martin (1992), "Convergence," Journal of Political Economy, 100: 223-251.

Benhabib, J. and M.M. Spiegel (1992), "The Role of Human Capital in Economic Development: Evidence from Aggregate Cross-Country and Regional U.S. Data," New York University.

Bental, B. and D. Peled (1992), "Endogenous Technical Progress and Growth: A Search Theoretic Approach." Technion, Haifa, Israel.

Coe, D.T. and E. Helpman (1993), "International R \&D Spillovers," NBER Working Paper No. 4444 .

Dinopoulos, E. (1994), "Schumpeterian Growth Theory: An Overview," Osaka City University Economic Review, 29:1-21.

Dowrick, S. and D. Nguyen (1989), "OECD Comparative Economic Growth 1950-85: Catch up and Convergence," American Economic Review, 79:1010-1030.

Evenson, R.E. and A.S. Englander (1994), "International Growth Linkages Between OECD Countries," Yale University.

Fagerberg, J. (1987), "A Technology Gap Approach to Why Growth Rates Differ," Research Policy, 16: 87-99. 
Fagerberg, J. (1994), "Technology and International Differences in Growth Rates," Journal of International Perspectives, 32: 1147-1175.

Gerschenkron, A. (1962), "Economic Backwandness in Historical Perspective. Cambridge, MA: Belknap Press.

Gomulks, S. (1990), The Theory of Technological Change and Economic Growth. London: Routledge.

Grossman, G.M. and E. Helpman (1991), Innovation and Growth in the Sobal Economy. Cambridge: MIT Press.

Grossman, G.M. and E. Helpman (1994), "Technology and Trade," in G.M. Grossman and K. Rogoff, editors, Handbook of International Economics, Volume 9. Amsterdam: NorthHolland.

Helfgott, S. (1993). "Patent Filing Costs Around the World." Journal of the Patent and Trademark Office Society, July: 567-580.

Helliwell, J. and A. Chung (1991), "Macroeconomic Convergence: International Transmission of Growth and Technical Progress," in P. Hooper and J.D. Richardson, editors, International Economic Transactions: Issues in Measurement and Empirical Research. University of Chicago Press.

IMF (1994), International Financial Statistics, June.

Jones, C.I., (1993), "Time Series Tests of Endogenous Growth Models." MIT.

Jovanovic, B. and S. Lach (1991), "The Diffusion of Technology and Inequality Among Nations." NBER Working Paper No. 9792.

Kortum, S. (1994), "A Model of Research, Patenting and Productivity Growth," NBER Working paper No. 4646 . 
Krugman, P.R (1979), “A Model of Innovation, Technology Transfer, and the World Distribution of Income," Journal of Political Economy, 87: 253-266.

Levin, R.C., A.K. Klevorick, R.R. Nelson and S.G. Winter (1987), "Appropriating the Returns From Industrial Research and Development," Brookings Papers on Economic Activity, 3:1987.

Lichtenberg, F. (1992), "R\&D Investment and International Productivity Differences," in $H$. Siebert, editor, Economic Growth in the World Economy, Symposium 1992. Turbingen: J.C.B. Mohr.

Mankiw, N.G., D. Romer and D.N. Weil (1992), "A Contribution to the Empirics of Economic Growth," Quarterly Journal of Economics, 107: 407-437.

Nelson, R.R. and E.S. Phelps (1966), "Investment in Humans, Technological Diffusion, and Economic Growth," American Economic Review, Papers and Proceedings, 56: 69-75.

OECD (1991), Basic Science and Technology Statistics. Paris.

Okada, Y. (1992), "Tokkyoseido no Ho to Keizaigaku," ("The Law and Economics of the Patent System") Staff Paper, Shinshu University.

Parente, S.L. and E.C. Prescott (1994), "Barriers to Technology Adoption and Development," Journal of Political Economy, 102: 298-321.

Pavitt, K. and L.G. Soete (1982), "International Differences in Economic Growth and the International Location of Innovation, ${ }^{n}$ in H. Giersch, editor, Emerging Technologies: Consequences for Economic Growth, Structural Change, and Employment. Tubingen: J.C.B. Mohr.

Penrose, E.T. (1951), The Economics of the International Patent System. Baltimore: The Johns Hopkins University Press. 
Press, W.H., B.P. Flannery, S.A. Teukolsky and W.T. Vetterling (1989). Numerical Recipes. New York: Cambridge University Press.

Putnam, J. (1993). "Who Invests in the International Patent System?" Vassar College.

Segerstrom, P.S. (1991), "Innovation, Imitation, and Economic Growth," Journal of Political Economy, 4:807-827.

Summers, R. and A. Heston (1991), "The Penn World Table (Mark 5): An Expanded Set of International Comparisons, 1950-1988," The Quarterly Journal of Economics, 106:327368.

WIPO (1990), Industrial Property Statistics, World Intellectual Property Organization, Geneva. Young, A. (1993), "Substitution and Complementarity in Endogenous Innovation," Quarterly Journal of Economics, 108: 775-808. 


\section{A List of Symbols}

\begin{tabular}{|c|c|}
\hline$Y_{n t}$ & Output in country $n$ at time $t$. \\
\hline$J$ & Range of inputs, $j \in[0, J]$. \\
\hline$X_{n t}(j)$ & Quantity of input $j$ in country $n$ at time $t$. \\
\hline$Z_{n t}(j)$ & State of the art of input $j$ in country $n$ at time $t$. \\
\hline$L_{n t}$ & Workforce in country $n$ at time $t$. \\
\hline$\alpha_{n t}$ & Productivity of resesrchers in country $n$ at time $t$. \\
\hline$\beta$ & Parameter of the distribution of research talent. \\
\hline$R_{n t}$ & Researchers in country $n$ at time $t$. \\
\hline$Q$ & Random varisble representing the quality of an idea. \\
\hline$F(q)$ & Distribution from which the quality of an ides is drawn. \\
\hline$\theta$ & Parameter of the quality distribution, $F(q)=1-q^{-\theta}$. \\
\hline$\tau$ & Random diffusion lag. \\
\hline$\epsilon_{\boldsymbol{n i}}$ & Rate of diffusion from country $i$ to $n$. \\
\hline$\mu_{\text {nt }}$ & Stock of ideas that have diffused to country $n$ by time $t$. \\
\hline$H_{n}(z \mid t)$ & Cumulative distribution of the state of the art in country $n$ at time $t$. \\
\hline$A_{\text {nt }}$ & Level of productivity in country $n$ at time $t$. \\
\hline$\psi$ & Euler's constant $(\approx .5772)$. \\
\hline$\iota_{n}^{\text {pat }}$ & Rate of imitation in country $n$ if invention is patented. \\
\hline$\iota_{n}^{\text {not }}$ & Rate of imitation in country $n$ if invention is not patented. \\
\hline$p_{n t}(j)$ & Price (in units of output) of input $j$ in country $n$ at time $t$. \\
\hline$w_{\text {nt }}$ & Wage (in units of output) of production workers in country $n$ at time $t$. \\
\hline$\pi_{n t}(z, q)$ & $\begin{array}{l}\text { Profit from marketing input of quality } q \text { in country } n \text { at } \\
\text { time } t \text { if the next best input has quality } z \text {. }\end{array}$ \\
\hline$V_{\text {nit }}^{k}(z, q)$ & Expected discounted value as of time $t$ in country $n$ of an invention \\
\hline
\end{tabular}


from country $i$ where the invention has quality $q$ and replaces an input of quality $z$. The index $k=$ pat, not specifies if it is patented.

$V_{\text {nit }}^{k}(q)$

$c_{\text {nit }}$

$\bar{q}_{\text {nit }}$

$P_{\text {nit }}$

$b_{\text {nit }}$

$V_{\text {nit }}$

$V_{\text {it }}$

$g$

$\Psi(a / g, b)$

$u_{n i}$

$\kappa_{1}(\theta)$

$\kappa_{2}(\theta)$

$y$

$\boldsymbol{x}$

$\theta$
Discount rate.

Expected value of $V_{\text {nit }}^{k}(z, q)$ before the sector (hence $z$ ) is known.

Cost of seeking protection in country $n$ from country $i$ at time $t$.

Cut-off quality to patent from country $i$

in country $n$ on an ides invented in $t$.

Number of ideas from country $i$ seeking protection in $n$ at time $t$.

Defined as $\mu_{n t} \bar{q}_{n i t}^{-\theta}$ (constant in steady state.)

Expected value of an invention from country $i$ in country $n$ at time

$t$, unconditional on its quality.

Expected value of an invention from country $i$ at time $t$.

Steady-state growth rate of $\mu$, the stock of diffused ideas.

Integral defined as $g \int_{0}^{\infty} e^{-a s} e^{-b e s s} d s$.

Normalized value of an invention from country $i$ in country $n$

defined as $V_{\text {nit }} \mu_{n t} / Y_{n t}$

Term relating productivity index to the wage.

Average value of the inverse of the mark-up of input prices over

the cost of producing them.

Vector of endogenous variables.

Vector of exogenous variables.

Vector of parameters. 


\section{B Mathematical Appendix}

We derive the time invariant probability density for the mark-up of input price over marginal cost (the wage) across sectors. This density shows up in our equation for the wage conditional on productivity (10) and our equation for the value of output conditional on the wage and the workforce in production (11). We begin by deriving those equations.

To derive the wage equation, start with the result that the quantity purchased of input $j$ is

$$
X(j)=\frac{Y}{J p(j)}=\frac{Y}{J w M(j)},
$$

where $M(j)$ is the mark-up for input $j$. Plugging this into the production function and rearranging,

$$
\ln w=\ln A-J^{-1} \int_{0}^{J} \ln M(j) d j
$$

But, if we know the density $g$ of $M$ we have,

$$
J^{-1} \int_{0}^{J} \ln M(j) d j=\int_{1}^{\infty} \ln m g(m ; \theta) d m .
$$

To derive the value of output equation, note that total profit across all sectors is,

$$
\int_{0}^{J}\left(1-M(j)^{-1}\right) \frac{Y}{J} d j=Y\left[1-\int_{1}^{\infty} m^{-1} g(m ; \theta) d m\right] .
$$

Therefore, since wages plus profits equal the value of output,

$$
Y \int_{1}^{\infty} m^{-1} g(m ; \theta) d m=w(L-R)
$$

Deriving the functional form of $g(m ; \theta)$ requires several steps. As we have defined it, the mark-up for input $j$ at a given time is equal to the quality of that input relative to the quality of the input that it surpassed. We begin by deriving the joint density for new innovations of the mark-up and the state of the art surpassed, denoted $l(m, z \mid t)$. We then integrate over sll past cohorts of innovations to obtain the distribution of the mark-up for those innovations that are still in use. 
First consider the distribution of the state of the art surpassed by innovations adopted at time $t$. This will not be the same as the distribution of the qualities of all inputs currently in use, equation (2), since low quality inputs are more likely to be surpassed than high quality inputs. Formally, we have,

$$
\operatorname{Pr}[Z \leq z \mid Q \geq Z, t]=\operatorname{Pr}[Z \leq z, Q \geq Z \mid t] / \operatorname{Pr}[Q \geq Z \mid t]=\frac{\int_{1}^{z}(1-F(x)) H^{\prime}(x \mid t) d x}{\int_{1}^{\infty}(1-F(x)) H^{\prime}(x \mid t) d x}
$$

where $F(x)=1-x^{-\theta}$ is the distribution from which the quality of ideas is drawn and $H^{\prime}(x \mid t)=$ $\theta \mu_{t} x^{-\theta-1} e^{\mu x^{-\theta}}$ is the density of the state of the art, the derivative of equation (2). Integrating out the denominator under the assumption that $\mu_{t}$ becomes arbitrarily large, we find that the density of the state of the art that is surpassed by innovations adopted at time $t$ is,

$$
\theta \mu_{t}^{2} z^{-(2 \theta+1)} e^{-\mu+z^{-\theta}}
$$

Without regard to the state of the art surpassed, the mark-up of an innovation adopted at time $t$ is drawn from the Pareto distribution. To see this, let $z$ be the state of the art surpassed,

$$
\operatorname{Pr}\left[\frac{Q}{z} \leq m \mid Q \geq z\right]=\frac{\operatorname{Pr}[z \leq Q \leq z m]}{\operatorname{Pr}[Q \geq z]}=\frac{F(z m)-F(z)}{1-F(z)}=1-m^{-\theta} .
$$

Therefore, multiplying the density of the state of the art surpassed by the density of the mark-up conditional on the state of the art surpassed,

$$
l(m, z \mid t)=\theta^{2} \mu_{t}^{2} m^{-\theta-1} z^{-(2 \theta+1)} e^{-\mu z^{-\theta}} .
$$

The derivation above tells us about the distribution of the mark-up for new innovations. To calculate the distribution of the mark-up for all inputs currently in use we need to keep track of the mark-up for innovations adopted years earlier that are still in use. This is made possible by the fact that the hazard rate faced by these earlier innovations depends on their quality, i.e. the product of their mark-up and the state of the art they surpassed. It is for this reason that we derived the joint density. The other ingredient is the rate at which innovations were being adopted in earlier periods. This is simply the rate at which ideas were diffusing 
at time $s$ multiplied by the fraction of those ideas that were useful at that time, i.e. $\dot{\mu}_{s} / \mu_{o}$. Combining these results, the distribution of the mark-up is,

$$
G\left(m^{\prime} \mid t\right)=\int_{-\infty}^{t} \frac{\dot{\mu}_{s}}{\mu_{s}} \int_{1}^{m^{\prime}} \int_{1}^{\infty} l(m, z \mid s) e^{-\left(\mu_{t}-\mu_{o}\right)(z m)^{-0}} d z d m d s
$$

Changing the variable of integration from $z$ to

$$
x=z^{-\theta}\left(\mu,+\mu_{t} m^{-\theta}-\mu, m^{-\theta}\right) \equiv z^{-\theta} \phi(m, s, t)
$$

and, noting that $\phi(m, s, t)$ becomes arbitrarily large over time, the inner-most integral is $\theta \mu_{s}^{2} \phi(m, s, t)^{-2} m^{-(\theta+1)}$. Thus, changing the order of integration,

$$
G\left(m^{\prime} \mid t\right)=\int_{1}^{m^{\prime}} \theta m^{-(\theta+1)} \int_{-\infty}^{t} \dot{\mu}_{s} \mu_{s} \phi(m, s, t)^{-2} d s d m
$$

Changing the variable of integration from $s$ to $\mu_{s}$,

$$
G\left(m^{\prime} \mid t\right)=\int_{1}^{m^{\prime}} \frac{\theta m^{-(\theta+1)}}{\left(1-m^{-\theta}\right)^{2}}\left(m^{-\theta}+\theta \ln m-1\right) d m
$$

After some rearranging, we see that the argument of this integral is exactly $g(m ; \theta)$, the density of the mark-up. 
Table 1: Exogenous Varisbles

\begin{tabular}{l|rrrrr}
\hline & Germany & France & U.K. & Japan & U.S. \\
\hline $\begin{array}{l}\text { Labor Force } \\
\text { (millions) }\end{array}$ & \multicolumn{7}{c}{} \\
\hline $\begin{array}{l}\text { Adjusted GDP } \\
\text { (\$ billions) }\end{array}$ & 1751 & 1299 & 921 & 3662 & 5876 \\
\hline Application costs & \multicolumn{6}{c}{} \\
(\$) to patent in: & 1066 & 1066 & 1066 & 3066 & 1066 \\
Germany & 992 & 992 & 992 & 3042 & 992 \\
France & 1200 & 1200 & 1200 & 4020 & 1200 \\
U.K. & 4772 & 4772 & 4772 & 9590 & 4772 \\
Japan & 3390 & 3440 & 1390 & 4210 & 1390 \\
U.S. &
\end{tabular}

Sources: Labor force is from Summers and Heston (1991).

Adjusted GDP is from IMF (1994) with R\&D expenditure from OECD (1991) subtracted. Costs of filing a patent application (including translation and agents fees) are from Helfgott (1993). The cost for a Japanese inventor filing an application in Japan is scaled up by a factor of 4.9 (see text for the rationale).

The ratio of application costs to adjusted GDP is assumed to be exogenous and constant in steady state. 
Table 2: Endogenous Variables

\begin{tabular}{l|rrrrr}
\hline & Germany & France & U.K. & Japan & U.S. \\
\hline $\begin{array}{l}\text { Productivity growth } \\
\text { in manufacturing }\end{array}$ & 0.035 & 0.035 & 0.035 & 0.035 & 0.035 \\
\hline $\begin{array}{l}\text { Relative productivity levels } \\
\text { in manufacturing }\end{array}$ & 0.82 & 0.76 & 0.58 & 0.82 & 1 \\
\hline $\begin{array}{l}\text { Adjusted research employment } \\
\text { in thousands }\end{array}$ & 97 & 41 & 74 & 289 & 477 \\
\hline Patent applications & \multicolumn{5}{c}{} \\
seeking protection in: & \multicolumn{5}{c}{ by inventors from } \\
Germany & 42872 & 4713 & 4114 & 12819 & 16310 \\
France & 12592 & 14921 & 3830 & 9340 & 15304 \\
U.K. & 12179 & 4590 & 24098 & 11371 & 17279 \\
Japan & 7246 & 2512 & 2407 & 62884 & 15374 \\
U.S. & 12483 & 4901 & 5805 & 29613 & 75632 \\
\hline
\end{tabular}

Sources: Manufacturing value added per hour is from

Van Ark (1992). Research employment is R\&D RSE's

employed in the business sector, OECD (1991) adjusted by

by the fraction of business sector R\&D which

is financed by either the business sector or from abroad.

Patent applications are from WIPO (1990). Domestic applications in Japan are scaled down by a factor of 4.9 (see text).

All data are 1988 values with the exception of productivity growth, which we average across countries from 1979-1989. 
Table 3: Fitted Parameters

\begin{tabular}{ll|r}
\hline Definition & Symbol & Fitted value \\
\hline Parameter of search distribution & $\theta$ & 1.60 \\
Parameter of talent distribution & $\beta$ & 0.012 \\
Number of markets (millions) & $J$ & 0.17 \\
Research productivity & $\alpha$ & 0.00015 \\
Imitation rates: & & \\
$\quad$ if not patented & $\iota^{\text {not }}$ & 0.226 \\
$\quad$ if patented at home & $\iota_{D}^{\text {pat }}$ & 0.000 \\
$\quad$ if patented abroad & $\epsilon_{F}^{p a t}$ & 0.221 \\
Diffusion rates from: & & \\
Germany & $\epsilon .1$ & 0.037 \\
France & $\epsilon .2$ & 0.0074 \\
U.K. & $\epsilon .3$ & 0.032 \\
Japan & $\epsilon .4$ & 0.020 \\
U.S. & $\epsilon .5$ & 0.0030 \\
Diffusion rates to: & & \\
Germany & $\epsilon_{1 .}$ & 1.73 \\
France & $\epsilon_{2}$ & 1.34 \\
U.K. & $\epsilon_{3 .}$ & 0.57 \\
Japan & $\epsilon_{4}$. & 0.87 \\
Diffusion rate domestic & $\epsilon_{D}$ & 9.77 \\
\hline We paramet. &
\end{tabular}

We parameterize $\epsilon_{n i}$ as $\epsilon_{n, \epsilon_{, i} \epsilon_{D}}$ where $\epsilon_{D}$ takes on the value 1 if $n \neq i$ and the value in the last row of the table if $n=i$ (we normslize $\epsilon_{5}=1$ ). 
Table 4: Model Fit

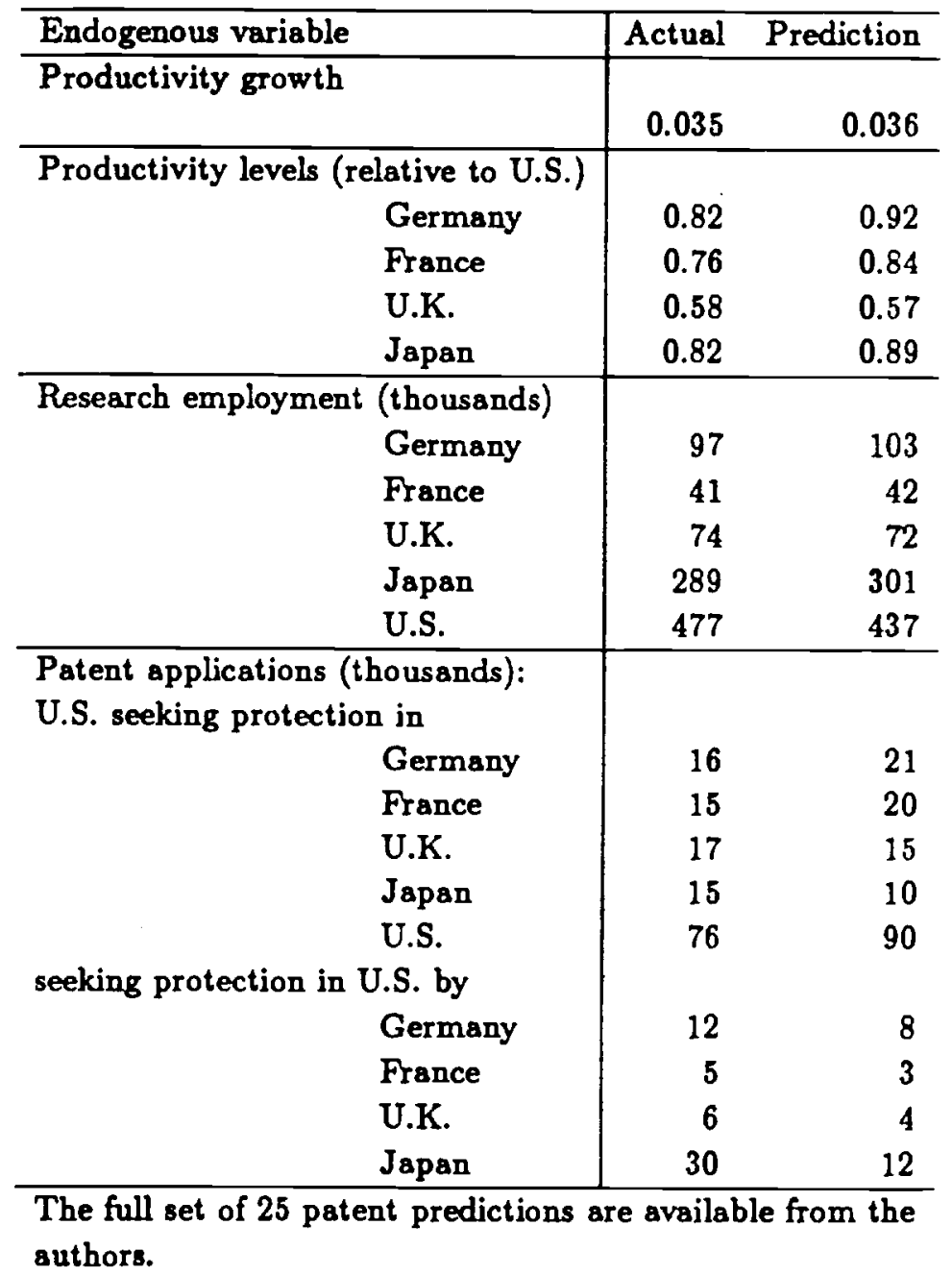

Table 5: Growth Decomposition

\begin{tabular}{l|rrrrr}
\hline Fraction of productivity & \multicolumn{5}{|c}{ Due to research performed in: } \\
growth in: & Germany & France & U.K. & Japan & U.S. \\
\hline Germany & 0.38 & 0.06 & 0.09 & 0.31 & 0.16 \\
France & 0.23 & 0.22 & 0.09 & 0.31 & 0.16 \\
U.K. & 0.24 & 0.05 & 0.30 & 0.29 & 0.12 \\
Japan & 0.16 & 0.03 & 0.06 & 0.65 & 0.09 \\
U.S. & 0.14 & 0.03 & 0.06 & 0.19 & 0.58 \\
\hline
\end{tabular}

Rows may not sum to 1 due to rounding. 
Table 6: Invention Value Decomposition

\begin{tabular}{l|rrrrr}
\hline Fraction of invention value & \multicolumn{5}{|c}{ For inventions originating in: } \\
from markets in: & Germany & France & U.K. & Japan & U.S. \\
\hline Germany & 0.80 & 0.02 & 0.04 & 0.02 & 0.00 \\
France & 0.03 & 0.90 & 0.03 & 0.01 & 0.00 \\
U.K. & 0.02 & 0.01 & 0.80 & 0.01 & 0.00 \\
Japan & 0.05 & 0.02 & 0.04 & 0.92 & 0.00 \\
U.S. & 0.10 & 0.04 & 0.09 & 0.04 & 0.99 \\
\hline
\end{tabular}

Columns may not sum to 1 due to rounding.

Table 7: Experiments with the Rate of Diffusion

\begin{tabular}{l|rrr}
\hline & Baseline & $\begin{array}{r}\text { Technological } \\
\text { isolation }\end{array}$ & $\begin{array}{r}\text { Borderless } \\
\text { diffusion }\end{array}$ \\
\hline Productivity growth & & & \\
& 0.036 & 0.033 & 0.062 \\
\hline Productivity levels (relative to the U.S.) & & & \\
Germany & 0.92 & 16.1 & 1.13 \\
France & 0.84 & 14.9 & 1.07 \\
U.K. & 0.57 & 10.4 & 0.85 \\
Japan & 0.89 & 16.7 & 0.96 \\
\hline Research employment (thousands) & & & \\
Germany & 103 & 91 & 186 \\
France & 42 & 40 & 67 \\
U.K. & 72 & 65 & 138 \\
Japan & 301 & 287 & 383 \\
U.S. & 437 & 430 & 398 \\
\hline In Baselin
\end{tabular}

In "Baseline" we repeat the predictions of the model from

table 4.

In "Technological isolation" we set the diffusion rates

between the U.S. and the other 4 countries equal to 0.0001 .

Since these diffusion rates are not zero, the U.S. still grows

at the same rate as the other 4 countries in steady state.

In "Borderless diffusion" we set $\epsilon D=9.77$ even

for $n \neq i$. 
Table 8: Experiments with the Strength of Patent Protection

\begin{tabular}{cl|rrr}
\hline Endogenous variable & Baseline & $\begin{array}{r}\text { No patent } \\
\text { protection }\end{array}$ & $\begin{array}{r}\text { Perfect patent } \\
\text { protection }\end{array}$ \\
\hline Productivity growth: & & & \\
& & 0.0356 & 0.0352 & 0.0358 \\
\hline Productivity levels (relative to U.S.): & & & \\
Germany & 0.92 & 0.93 & 0.93 \\
& France & 0.84 & 0.84 & 0.84 \\
U.K. & 0.57 & 0.57 & 0.57 \\
Japan & 0.89 & 0.89 & 0.89 \\
\hline Research employment (thousands): & & & \\
Germany & 103 & 36 & 314 \\
& France & 42 & 8 & 90 \\
U.K. & 72 & 22 & 220 \\
Japan & 301 & 60 & 558 \\
U.S. & 437 & 40 & 504 \\
\hline
\end{tabular}

In "Baseline" we repeat the predictions of the model from

table 4.

In "No patent protection" we set all imitation rates equal to $\iota^{\text {not }}=.226$.

In "Perfect patent protection" we set all imitation rates, conditional

on patenting, equal to 0 . 